\title{
BMJ Open Determinants of maternal knowledge of neonatal danger signs among postpartum mothers in Southern Ethiopia: institutional-based cross- sectional study
}

\author{
Ayenew Mose (D) , ${ }^{1}$ Haimanot Abebe (D) , ${ }^{2}$ Solomon Shitu (D) , ${ }^{2}$ Habtamu Shimels ${ }^{3}$
}

To cite: Mose A, Abebe H, Shitu S, et al. Determinants of maternal knowledge of neonatal danger signs among postpartum mothers in Southern Ethiopia: institutional-based crosssectional study. BMJ Open 2021;11:e048888. doi:10.1136/ bmjopen-2021-048888

- Prepublication history for this paper is available online. To view these files, please visit the journal online (http://dx.doi org/10.1136/bmjopen-2021048888).

Received 12 January 2021 Accepted 18 August 2021

\section{Check for updates}

(C) Author(s) (or their employer(s)) 2021. Re-use permitted under CC BY-NC. No commercial re-use. See rights and permissions. Published by BMJ.

${ }^{1}$ Department of Midwifery, Wolkite University, Welkite, Ethiopia

${ }^{2}$ Wolkite University, Wolkite, Ethiopia

${ }^{3}$ Department of Nursing, Debre Tabor University, Debre Tabor, Ethiopia

Correspondence to Mr Ayenew Mose; ayenew8484@gmail.com

\section{ABSTRACT}

Objective The main aim of this study was to assess knowledge of neonatal danger signs and associated factors among postpartum mothers in Southern Ethiopia. Setting Gurage zone, Southern Ethiopia.

Study participants A total of 608 postpartum mothers were involved in this study.

Methods An institutional-based cross-sectional study design was conducted among postpartum mothers attending Gurage zone public health facilities of Southern Ethiopia from 1 January 2020 to 30 January 2020. Results Knowledge of neonatal danger signs among postpartum mothers was $48.2 \%(95 \% \mathrm{Cl} 44.4 \%$ to $52.3 \%$ ). Mothers resided in an urban area (adjusted OR, $\mathrm{AOR}=1.67,95 \% \mathrm{Cl} 1.11$ to 2.50 ), having antenatal followup (AOR=1.49, 95\% $\mathrm{Cl} 1.02$ to 2.18), mothers who had got breastfeeding counselling (AOR=3.43, 95\% $\mathrm{Cl} 1.89$ to 4.75), mothers who had got postnatal care counselling (AOR=1.53, 95\% Cl 1.08 to 2.18), multiparous mothers ( $A O R=1.37,95 \% \mathrm{Cl} 1.24$ to 2.19 ) and mothers who had good practice of essential newborn care (AOR $=1.53,95 \%$ $\mathrm{Cl} 1.06$ to 2.21) were factors significantly associated with maternal knowledge of neonatal danger signs.

Conclusions Knowledge of neonatal danger signs was low in the study area. Mothers resided in an urban area, having antenatal follow-up, mothers who had got breastfeeding counselling, mothers who had got postnatal care counselling, multiparous mothers and good practice of essential neonatal care were factors associated with maternal knowledge of neonatal danger signs. Therefore, healthcare workers should encourage mothers to have antenatal follow-up and provide postnatal care counselling regarding key neonatal danger signs before discharge from the health facilities.

\section{INTRODUCTION}

Neonatal danger signs (NDSs) are nonspecific clinical features that indicate severe illness in the first 28 days of the neonatal period. ${ }^{1}$ According to $\mathrm{WHO}$, there are nine NDSs (ie, unable to breastfeed, fever, severe chest indrawing, hypothermia, convulsions, jaundice/yellow palms/soles/eyes, birth
Strengths and limitations of this study

- This study identifies the gaps in knowledge of neonatal danger signs among mothers that help to improve maternal health-seeking behaviour and neonatal health.

- This study used an appropriate statistical method to identify associated factors.

- This study did not show the relationship between cause and effect due to the nature of the crosssectional study design.

- The study might share hawthorn bias/participants might change their behaviour when they feel they are being observed/in the observational checklist section of data collection.

asphyxia/birthing difficulties, umbilicus infection and eye discharge). ${ }^{2}$

Globally about 2.5 million newborns die in 2017, with approximately 7000 newborns dying every day. About $99 \%$ of neonatal deaths occurred in low-income and middle-income countries, and $75 \%$ of the newborn were dying within the first weeks of neonatal life. ${ }^{3}$ The burden of neonatal mortality is higher in sub-Saharan Africa, 27 neonatal deaths per 1000 live births followed by Central and Southern Asia, 24 neonatal deaths per 1000 live births. ${ }^{4}$ In Ethiopia, neonatal mortality declined from 49 per 1000 live births in 2000 to 28 per 1000 live births in $2016 .^{5}$

According to the Mini Ethiopian Demographic Health Survey 2019 (MEDHS), neonatal mortality remains unacceptably high in Ethiopia despite extensive work that has been done. ${ }^{6}$ For instance, successful implementations of the National Newborn and Child Survival Strategy, ${ }^{7}$ utilisation of Integrated Management of Neonatal and Childhood Illness, ${ }^{8}$ and Community Based Newborn Care practice were some of the 
activities done by the Ethiopian government to reduce neonatal mortality. ${ }^{9}$

In 2014, WHO assembly endorsed Every Newborn Action Plan states that ending preventable neonatal deaths and stillbirth globally. ${ }^{10}$ Likewise, Ethiopia has promised to reduce neonatal mortality to 12 or fewer per 1000 live births by 2030 Sustainable Development Goals. ${ }^{11}$

Evidence shows that adequate maternal knowledge of NDSs has immense benefits to recognise neonatal illness, initiate early medical treatment of neonates in the nearby health facilities, and improve maternal health-seeking behaviour. Therefore, to achieve Every Newborn Action Plan and Sustainable Development Goals, adequate knowledge of mothers about NDSs is very crucial. ${ }^{12} 13$

Maternal knowledge of NDSs in Ethiopia was found between $20.3 \%$ in Ambo town and 60\% in Debre Tabor town. ${ }^{14-16}$ Antenatal care (ANC) follow-up, postnatal follow-up and higher education status of mothers were factors associated with good knowledge of mothers towards NDSs. ${ }^{16}$ Overall, in the study area, there was no clear evidence on knowledge of NDSs and associated factors among postpartum mothers. Therefore, the main aim of this study was to investigate knowledge of NDSs and to identify associated factors among postpartum mothers attending Gurage zone public health facilities of Southern Ethiopia.

\section{METHODS}

\section{Study setting, design and period}

The southern part of Ethiopia is 1 of the 11 regions of Ethiopia. Gurage Zone is found in the southern part of Ethiopia. It is located $153 \mathrm{~km}$ southwest of Addis Ababa, the capital city of Ethiopia. Gurage Zone has 15 districts and Wolkite town is the administrative centre of the Zone. According to the Central Statistical Agency of Ethiopia in 2007, this zone has a total population of 1279 646, of whom 622078 are men and 657568 are women. There are 7 hospitals and 72 health centres that provide healthcare services for the catchment population. All hospitals and health centres provide delivery services for pregnant mothers 24 hours per day. An institutional-based crosssectional study design was employed among postpartum mothers in Southern Ethiopia from 1 January 2020 to 30 January 2020.

\section{Source population and study population}

All postpartum mothers who had a live birth attending Gurage zone public health facilities of southern Ethiopia were the source population. All postpartum mothers in selected public health facilities of Gurage zone were considered as the study population.

\section{Inclusion and exclusion criteria}

Postpartum mothers who delivered a healthy newborn were included. Mothers who had a sick newborn and admitted to neonatal intensive care unit, unable to respond, lost their newborn or develop labour complication were excluded.

\section{Sample size determination and sampling procedure}

A single population proportion formula was used to calculate the sample size for this study by considering the following assumption; $(p=40.09 \%)$ proportion of good maternal knowledge of NDSs in Arba Minch General Hospital, ${ }^{17}$ 95\% CI, 5\% margin of error, design effect of $(\mathrm{d}=1.5)$ and non-response rate of $10 \%$. The final sample size was 608. A multistage sampling technique was used. In the primary sampling stage, Gurage Zone has a total of 7 hospitals and 74 health centres that all are provided delivery services. Of these, 2 hospitals and 22 health centres were selected using a simple random sampling technique, based on $30 \%$ WHO recommendation to maintain generalisability. In the secondary stage, study participants (postpartum mothers) who fulfilled the inclusion criteria were selected using a systematic random sampling technique based on each health facilities client follow till we reach the final sample size.

\section{Data collection tools and quality control}

The tools were adopted after reviewing relevant literature such as MEDHS to adopt questionnaires regarding sociodemographic characteristics, Bulto et al and Bayih et $a f^{6141517}$ to adopt questionnaires regarding obstetric healthcare service characteristics, maternal knowledge of neonatal dangers signs and essential newborn care practice. The tool contains four parts; sociodemographic characteristics of mothers, obstetric health service characteristics, maternal knowledge of NDSs and maternal essential newborn care practice. A total of 11 health professionals (7 BSc midwife/nurses and 3 MSc holder supervisors) who are not working in the study sites were recruited for data collection. To ensure data quality, a pretest of the questionnaires (5\%) on non-selected health facilities was done. Internal consistency (reliability) of the items (0.84) was checked by using Cronbatch's alpha in SPSS V.23. Also, 2 days (1-day theoretical and 1-day demonstration particularly on the observation checklist) training were given on data collection techniques for both data collectors and supervisors. Structured and face-toface exit interview of postpartum mothers after receiving delivery service was used to collect data on demographic variables, maternal knowledge of NDSs and obstetric health service characteristics. However, data on maternal essential newborn care practice were collected using an observational clinical checklist during a postpartum stay of mothers soon after birth and before maternal discharge from the health facilities.

\section{Data processing and analysis}

Questionnaires were entered into Epi-Data V.4.2.0 and exported into SPSS V.23 for analysis. Descriptive analysis results were presented in the form of texts, tables, percentages, mean and SD. Bivariate logistic regression analysis was used to determine the association of each 
independent variable with the outcome variable. Values of $\mathrm{p}<0.25^{17}$ result in the bivariate logistic regression model were included in multivariate logistic regression to control possible confounders. The direction and strength of statistical association were measured by OR with 95\% CI. The adjusted OR (AOR) along with 95\% CI was estimated to identify the associated factors of maternal knowledge of NDSs by using multivariate analysis. A $\mathrm{p}<0.05$ was considered as a cut-off point to declare a result as a statistically significant association.

\section{Operational definitions}

Key NDSs: These are a different sign that indicates the abnormal condition of the newborn in the first 28 days (neonatal period). ${ }^{2}$

Good knowledge of mothers about NDSs: According to WHO, the followings are recognised NDSs: breastfeeding difficulties, neonatal fever, severe chest indrawing, neonatal hypothermia, neonatal convulsions, neonatal jaundices, neonatal unconsciousness, neonatal umbilical infection and neonatal eye discharge. ${ }^{2}$ The above nine NDSs were used to assess the level of maternal knowledge of NDSs. It was a 'yes' and 'no' question, having equal weight. Therefore, those mothers who had scored more than or equal to three questions correctly were interpreted as having good knowledge of NDSs. ${ }^{18} 19$

Poor knowledge of mothers about NDSs: Those mothers who had scored less than 3 NDSs were coded as poor knowledge. The cut-off point (3) was taken from a study conducted in the northern part of Ethiopia and others similar studies, which had a similar population with our study area in different characteristics such as accessing healthcare service and utilisation of basic and comprehensive obstetric health service. ${ }^{18} 19$

Essential newborn care practice: According to the WHO guideline, essential newborn care practice includes early initiation of breast feeding, skin-to-skin contact (SSC), thermal care, colostrum feeding, cord care and positioning of a neonate. ${ }^{2}$ Observational checklists were used to assess essential newborn care practices. Those mothers who had correctly practised more than or equal to three essential newborn cares were coded as a good practice and less than three were coded as a poor practice. ${ }^{20}$

\section{Patient and public involvement}

In this study, neither patient nor public was involved in the study design, or conduct, or reporting, or dissemination plans of our research.

\section{RESULTS}

\section{Socio demographic characteristics}

A total of 608 mothers were involved making a response rate of $99 \%$. The mean $( \pm)$ age of study participants was $27.38( \pm 4.809 \mathrm{SD})$ years. About $374(61.5 \%)$ were aged from 25 to 34 years old. Regarding ethnicity, 447 (73.5\%) of the respondents were Gurage. Out of the total respondents, $398(65.5 \%)$ were housewives by occupation, and
Table 1 Sociodemographic characteristics of postpartum mothers in Southern Ethiopia, $2020(n=608)$

\begin{tabular}{|c|c|c|c|}
\hline Variables & Categories & Frequency & $\begin{array}{l}\text { Percentage } \\
(\%)\end{array}$ \\
\hline \multirow[t]{3}{*}{ Maternal age } & $15-24$ & 164 & 27 \\
\hline & $25-34$ & 374 & 61.5 \\
\hline & $\geq 35$ & 70 & 11.5 \\
\hline \multirow[t]{3}{*}{ Religion } & Orthodox & 380 & 62.5 \\
\hline & Muslim & 172 & 28.3 \\
\hline & Protestant & 56 & 9.2 \\
\hline \multirow[t]{3}{*}{ Ethnicity } & Gurage & 447 & 73.5 \\
\hline & Amhara & 123 & 20.2 \\
\hline & Oromo & 38 & 6.3 \\
\hline \multirow{4}{*}{$\begin{array}{l}\text { Maternal } \\
\text { education } \\
\text { statues }\end{array}$} & $\begin{array}{l}\text { No formal } \\
\text { education }\end{array}$ & 157 & 25.8 \\
\hline & $\begin{array}{l}\text { Primary } \\
\text { education (1-8) }\end{array}$ & 240 & 39.5 \\
\hline & $\begin{array}{l}\text { Secondary } \\
\text { education (9-12) }\end{array}$ & 134 & 22 \\
\hline & $\begin{array}{l}\text { College and } \\
\text { above }\end{array}$ & 77 & 12.7 \\
\hline \multirow{2}{*}{$\begin{array}{l}\text { Mother } \\
\text { household } \\
\text { head }\end{array}$} & Yes & 484 & 79.6 \\
\hline & No & 124 & 20.4 \\
\hline \multirow{4}{*}{$\begin{array}{l}\text { Maternal } \\
\text { occupation }\end{array}$} & House wife & 398 & 65.5 \\
\hline & Merchant & 81 & 13.3 \\
\hline & $\begin{array}{l}\text { Government } \\
\text { employer }\end{array}$ & 111 & 18.3 \\
\hline & Daily labourer & 18 & 3.0 \\
\hline \multirow{2}{*}{$\begin{array}{l}\text { Maternal } \\
\text { residence }\end{array}$} & Rural & 475 & 78 \\
\hline & Urban & 133 & 22 \\
\hline \multirow[t]{2}{*}{ Infant sex } & Male & 344 & 56.6 \\
\hline & Female & 264 & 43.4 \\
\hline
\end{tabular}

$157(25.8 \%)$ of mothers did not have formal education (table 1).

\section{Obstetric health service characteristics}

In this study, 507 (83.4\%) of mothers were multiparous. Three hundred and twenty-two (53\%) of postpartum mothers had an antenatal follow-up. Of these, 106 (33\%) of mothers had greater than or equal to four times ANC follow-up and $198(61.5 \%)$ of mothers had got breastfeeding counselling during ANC follow-up. About 364 (59.9\%) gave birth at a health institution and 354 (58.3\%) of mothers had got postpartum care counselling before discharge from the health facilities (table 2).

\section{Maternal knowledge of NDSs}

This study revealed that the level of maternal knowledge of NDSs was $48.2 \%$ (95\% CI $47.7 \%$ to $55.8 \%$ ). Neonatal fever was frequently mentioned by $387(64 \%)$ of 
Table 2 Obstetric health service characteristics of postpartum mothers in southern Ethiopia, $2020(n=608)$

\begin{tabular}{|c|c|c|c|}
\hline Variables & Categories & Frequency & $\begin{array}{l}\text { Percentage } \\
(\%)\end{array}$ \\
\hline \multirow[t]{2}{*}{ Parity } & Primiparous & 101 & 16.6 \\
\hline & Multiparous & 507 & 83.4 \\
\hline \multirow{2}{*}{$\begin{array}{l}\text { Antenatal care } \\
\text { (ANC) follow-up }\end{array}$} & Yes & 322 & 53 \\
\hline & No & 286 & 47 \\
\hline \multirow{4}{*}{$\begin{array}{l}\text { No of ANC } \\
\text { follow-up }(n=322)\end{array}$} & 1 & 42 & 13 \\
\hline & 2 & 34 & 10.5 \\
\hline & 3 & 140 & 43.5 \\
\hline & $\geq 4$ & 106 & 33 \\
\hline \multirow{2}{*}{$\begin{array}{l}\text { Breastfeeding } \\
\text { counselling }\end{array}$} & Yes & 198 & 61.5 \\
\hline & No & 124 & 38.5 \\
\hline \multirow[t]{2}{*}{ Place of delivery } & $\begin{array}{l}\text { Health } \\
\text { institution }\end{array}$ & 515 & 84.7 \\
\hline & Home & 93 & 15.3 \\
\hline \multirow[t]{2}{*}{ Mode of delivery } & Vaginal & 444 & 73 \\
\hline & $\begin{array}{l}\text { Caesarean } \\
\text { section }\end{array}$ & 164 & 27 \\
\hline \multirow{2}{*}{$\begin{array}{l}\text { Postnatal care } \\
\text { counselling }\end{array}$} & Yes & 354 & 58.2 \\
\hline & No & 254 & 41.8 \\
\hline \multirow{2}{*}{$\begin{array}{l}\text { Pregnancy } \\
\text { planned }\end{array}$} & Yes & 329 & 54.1 \\
\hline & No & 279 & 45.9 \\
\hline \multirow{2}{*}{$\begin{array}{l}\text { Childbirth } \\
\text { complication }\end{array}$} & Yes & 92 & 15.1 \\
\hline & No & 516 & 84.9 \\
\hline \multirow{2}{*}{$\begin{array}{l}\text { Participated in } \\
\text { ANC group }\end{array}$} & Yes & 322 & 53.0 \\
\hline & No & 286 & 47.0 \\
\hline
\end{tabular}

postpartum mothers and convulsion was the least danger sign mentioned by 69 (11.3\%) of mothers (table 3 ).

\section{Observed maternal essential newborn care practice}

A total of 608 mothers with a live newborn were observed for essential newborn care practice in each selected health facility soon afterbirth before discharge from the health facilities. Among the total observed study participants, $243(40 \%)$ of postpartum mothers had good practice of essential neonatal care and the remaining $365(60 \%)$ of mothers had poor practice towards essential neonatal care. A small number of mothers was practised SSC 117 $(19.2 \%)$ and $544(89.5 \%)$ of mothers feed colostrum (first breast milk) to their newborns (table 4).

\section{Factors associated with maternal knowledge of NDSs}

On the binary logistic regression model analysis, mothers resided in an urban area, multiparous mothers, having ANC follow-up, mothers who had got breastfeeding counselling, mothers who had got postnatal care counselling, mothers who had participated in an ANC group and good practice of essential newborn care were factors associated with maternal knowledge of NDSs.
Table 3 Knowledge of neonatal danger signs among postpartum mothers in Southern Ethiopia, $2020(n=608)$

\begin{tabular}{|c|c|c|c|}
\hline Variables & Categories & Frequency & $\begin{array}{l}\text { Percentage } \\
(\%)\end{array}$ \\
\hline \multirow[t]{2}{*}{ Fever } & Yes & 387 & 63.7 \\
\hline & No & 221 & 36.3 \\
\hline \multirow[t]{2}{*}{ Convulsions } & Yes & 69 & 11.3 \\
\hline & No & 539 & 88.7 \\
\hline \multirow[t]{2}{*}{ Birth asphyxia } & Yes & 234 & 38.5 \\
\hline & No & 374 & 61.5 \\
\hline \multirow[t]{2}{*}{ Umbilical infection } & Yes & 160 & 26.3 \\
\hline & No & 448 & 73.7 \\
\hline \multirow{2}{*}{$\begin{array}{l}\text { Severe chest in } \\
\text { drawing }\end{array}$} & Yes & 121 & 19.9 \\
\hline & No & 487 & 80.1 \\
\hline \multirow[t]{2}{*}{ Hypothermia } & Yes & 86 & 14.1 \\
\hline & No & 522 & 85.9 \\
\hline \multirow[t]{2}{*}{ Eye discharge } & Yes & 79 & 13 \\
\hline & No & 529 & 87 \\
\hline \multirow{4}{*}{$\begin{array}{l}\text { Newborn unable } \\
\text { to breastfeed } \\
\text { Jaundice } \\
\text { (yellowish } \\
\text { discolouration of } \\
\text { skin) }\end{array}$} & Yes & 298 & 48.2 \\
\hline & No & 310 & 51.8 \\
\hline & Yes & 490 & 80.6 \\
\hline & No & 118 & 19.4 \\
\hline
\end{tabular}

On the multivariable logistic regression model after controlling the confounding variables, mothers resided in an urban area, multiparous mothers, having ANC follow-up, mothers who had got breastfeeding counselling, mothers who had got postnatal care counselling and good practice of essential neonatal care were factors associated with good knowledge of mothers towards NDSs.

Mothers who had resided in an urban area were 1.67 times more likely knowledgeable about NDSs than those mothers who had resided in rural areas $(\mathrm{AOR}=1.67,95 \%$ CI 1.11 to 2.50). Multiparous mothers were 1.37 times more likely knowledgeable than those mothers who were primiparous mothers (AOR=1.37, 95\% CI 1.24 to 2.19). Mothers who had ANC follow-up were 1.49 times more likely knowledgeable than those mothers who did not have ANC follow-up (AOR=1.49, 95\% CI 1.02 to 2.18). Mothers who had got breastfeeding counselling during ANC visit were 3.43 times more likely knowledgeable than those mothers who did not receive breastfeeding counselling (AOR=3.43, 95\% CI 1.89 to 4.75). Mothers who have got postnatal care counselling before discharge from the health facility were 1.53 times more likely knowledgeable than those mothers who did not get postnatal care counselling (AOR $=1.53$, 95\% CI 1.08 to 2.18). Mothers who had good practice of essential newborn care were 1.5 times more likely knowledgeable than those mothers who had a poor practice of essential newborn care $(\mathrm{AOR}=1.5$, 95\% CI 1.06 to 2.21) (table 5). 
Table 4 Observed essential newborn practice among postpartum mothers in Southern Ethiopia, 2020 ( $n=608)$

\begin{tabular}{llll}
\hline Variables & Observed & Frequency & $\begin{array}{l}\text { Percentage } \\
\text { (\%) }\end{array}$ \\
\hline Skin-to-skin & Yes & 117 & 19.2 \\
contact & No & 491 & 80.8 \\
Initiation of early & Yes & 253 & 41.6 \\
breast feeding & No & 355 & 58.4 \\
Thermal care & Yes & 491 & 80.8 \\
& No & 117 & 19.2 \\
Colostrum & Yes & 544 & 89.5 \\
feeding & No & 64 & 10.5 \\
Cord care & Yes & 255 & 42 \\
& No & 358 & 58 \\
Good position of & Yes & 377 & 62 \\
neonates & No & 231 & 38 \\
\hline
\end{tabular}

\section{DISCUSSION}

The main aim of this study was to investigate knowledge of NDSs and associated factors among postpartum mothers. This study found that knowledge of NDSs among postpartum mothers was low. Mothers resided in an urban area, multiparous mothers, having ANC follow-up, mothers who had got breastfeeding counselling, mothers who had got postnatal care counselling and mothers who had good practice of essential newborn care were factors associated with good knowledge of NDSs among postpartum mothers.

In this study, the prevalence of knowledge of NDSs among postpartum mothers was $48.2 \%$. The finding was lower than studies conducted in Debre Tabor, northwest Ethiopia $61.7 \%{ }^{15}$ and India $50 \% .^{21}$ However, the finding was higher than studies conducted in Kenya $15.5 \%{ }^{22}$ Nigeria $30 \%,{ }^{12}$ Saudi Arabia $37 \%^{23}$ and various studies in Ethiopia. ${ }^{141624}$ The possible explanation for variations of the findings might be due to differences in access to healthcare service, area of residence, sample size determination and geographical variations. Additionally, the differences in the cut of point to declare good knowledge and poor knowledge of mothers about NDS

Mothers who resided in an urban area were 1.67 times more likely knowledgeable than those mothers who resided in a rural area. The possible justification might be those mothers who resided in an urban area might have better access to quality healthcare service, opportunity to access mass media that helps them to enhance their awareness about NDSs. The above explanation was supported by a study conducted in Northwest Ethiopia reported that those mothers who have access to mass media such as television and radio were more knowledgeable than those mothers who did not have access to mass media. ${ }^{25}$

Mothers who had antenatal follow-up were 1.49 times more likely knowledgeable than those mothers who did not have an antenatal follow-up. The finding was in line with various studies conducted in Ethiopia. ${ }^{13} 151626$ The possible justification might be those mothers who had ANC follow-up might receive antenatal health education, particularly NDSs during their antenatal follow-up. However, the finding was inconsistent with a study conducted in Uganda. ${ }^{27}$ The study conducted in Uganda shows that there was no association between ANC follow-up and knowledge of NDSs. The possible explanation might be healthcare providers might not provide NDS counselling for mothers during ANC follow-up.

Mothers who have got breastfeeding counselling during ANC visits were 3.4 times more likely knowledgeable than those mothers who did not get breastfeeding counselling. The possible explanation might be those mothers who had got breastfeeding counselling might have more opportunities of enhancing their awareness regarding NDSs. On the other hand, mothers who had received postnatal care counselling before discharge from the healthcare facility were 1.5 times more likely knowledgeable about NDSs compared with those mothers who did not receive postnatal care counselling. The finding was comparable with studies conducted in various study conducted in Ethiopia. ${ }^{13141728}$ The possible explanation might be those mothers who had got postnatal care counselling might receive health education from healthcare providers regarding NDSs since NDS is one of the essential components of postpartum care counselling. Additionally, postpartum care counselling is a provision of adequate counselling on early identification of maternal and NDSs after birth and enhancing maternal healthseeking behaviour. It is, therefore, crucial to provide postpartum care counselling for all mothers before discharge from the healthcare facilities.

Multiparous mothers were 1.37 times more likely knowledgeable than those mothers who were primiparous. The finding was in agreement with studies done in Harar town ${ }^{24}$ and Bangladesh. ${ }^{29}$ The possible explanation might be those mothers who gave birth more than two times might have multiple exposures to the healthcare providers that enable them to have awareness about NDSs compared with those primiparous mothers.

Mothers who had a good practice of essential newborn care were 1.5 times more likely knowledgeable about NDSs than those who had a poor practice of essential newborn care. The finding was consistent with a study conducted in Gonder, northern Ethiopia. ${ }^{15}$ The possible explanation might be during the period of essential newborn care practice mothers might be able to recognise different types of NDSs including neonatal birthing patterns, breastfeeding difficulties of newborns, neonatal hypothermia and neonatal fever.

This study shows that the majority of mothers were mentioned fever/newborn body hotness/as a common NDS. The finding was comparable with studies done in Bangladesh $^{29}$ and Ethiopia. ${ }^{25}$ The possible justification could be due to newborn body hotness might easily 
Table 5 Bivariate and multivariate regression analysis to identify factors associated with maternal knowledge of neonatal danger signs among postpartum mothers in Southern Ethiopia, $2020(n=608)$

\begin{tabular}{|c|c|c|c|c|c|}
\hline \multirow[b]{2}{*}{ Variables } & \multirow[b]{2}{*}{ Categories } & \multicolumn{2}{|c|}{$\begin{array}{l}\text { Maternal knowledge of } \\
\text { neonatal danger signs }\end{array}$} & \multirow[b]{2}{*}{ COR (95\% Cl) } & \multirow[b]{2}{*}{ AOR $(95 \% \mathrm{Cl})$} \\
\hline & & Poor (\%) & Good (\%) & & \\
\hline \multirow[t]{3}{*}{$\begin{array}{l}\text { Maternal } \\
\text { educational status }\end{array}$} & $\begin{array}{l}\text { Secondary and } \\
\text { above }\end{array}$ & $80(13)$ & $85(14)$ & 1.36 (0.91 to 2.05$)$ & 1.21 (0.78 to 1.86$)$ \\
\hline & Primary education & $117(19)$ & $116(19)$ & 1.27 (0.87 to 1.85$)$ & 1.12 (0.75 to 1.65$)$ \\
\hline & No formal education & $118(19.4)$ & $92(15)$ & 1 & 1 \\
\hline \multirow[t]{2}{*}{ Residence } & Rural & $258(42.4)$ & $217(36)$ & 1 & 1 \\
\hline & Urban & $57(9.3)$ & $76(12.5)$ & 1.59 (1.08 to 2.34$)$ & $1.67(1.11 \text { to } 2.50)^{\text {*^ }}$ \\
\hline \multirow[t]{2}{*}{ Parity } & Primiparous & $62(10)$ & $39(6.4)$ & 1 & 1 \\
\hline & Multiparous & 253 (41.6) & $254(41.8)$ & 1.59 (1.34 to 2.29$)^{*}$ & $1.37(1.24 \text { to } 2.19)^{*}$ \\
\hline \multirow[t]{2}{*}{ Antenatal follow-up } & No & $106(17.4)$ & $65(10.7)$ & 1.00 & \\
\hline & Yes & $209(34)$ & $228(37.5)$ & $1.78(1.24 \text { to } 2.55)^{\star}$ & $1.49(1.02 \text { to } 2.18)^{\star}$ \\
\hline \multirow{2}{*}{$\begin{array}{l}\text { Breastfeeding } \\
\text { counselling }\end{array}$} & No & $98(30.4)$ & $26(8.1)$ & 1 & 1 \\
\hline & Yes & $94(29.2)$ & 104 (32.3) & $4.17(2.85 \text { to } 5.88)^{*}$ & $3.43(1.89 \text { to } 4.75)^{\text {*x }}$ \\
\hline \multirow[t]{2}{*}{ Mode of delivery } & Vaginal & $238(39)$ & 206 (33.9) & 1.67 (0.84 to 2.45$)$ & 1.23 (0.75 to 2.13$)$ \\
\hline & Caesarean section & $108(17.8)$ & $56(9.2)$ & 1 & 1 \\
\hline \multirow[t]{2}{*}{ Place of delivery } & Home & $45(7.4)$ & $48(7.9)$ & 1 & 1 \\
\hline & Health institution & $230(37.8)$ & $284(46.7)$ & 1.16 (0.97 to 2.85$)$ & $1.42(0.91$ to 2.44$)$ \\
\hline \multirow{2}{*}{$\begin{array}{l}\text { Postnatal care } \\
\text { counselling }\end{array}$} & No & $150(24.7)$ & $99(16.3)$ & 1.00 & \\
\hline & Yes & $165(27)$ & $194(32)$ & $1.78(1.28 \text { to } 2.47)^{\star}$ & $1.53(1.08 \text { to } 2.18)^{\star}$ \\
\hline \multirow{2}{*}{$\begin{array}{l}\text { Childbirth } \\
\text { complication }\end{array}$} & No & $57(9.3)$ & $48(7.9)$ & 1 & 1 \\
\hline & Yes & $258(42.3)$ & $245(40.3)$ & 1.13 (0.74 to 1.72$)$ & 1.40 (0.89 to 2.19$)$ \\
\hline \multirow{2}{*}{$\begin{array}{l}\text { Participated in } \\
\text { an antenatal care } \\
\text { group }\end{array}$} & No & $139(22.8)$ & $104(104)$ & 1 & 1 \\
\hline & Yes & $176(28.9)$ & $189(31)$ & $1.44(1.04 \text { to } 1.99)^{\star}$ & 0.70 (0.49 to 1.02$)$ \\
\hline \multirow{2}{*}{$\begin{array}{l}\text { Maternal essential } \\
\text { newborn care } \\
\text { practice }\end{array}$} & Poor practice & $212(34.8)$ & $153(25)$ & 1 & 1 \\
\hline & Good practice & 103 (16.9) & $140(23)$ & $1.88(1.36 \text { to } 2.62)^{*}$ & $1.5(1.06 \text { to } 2.21)^{*}$ \\
\hline
\end{tabular}

Hosmer and Lemeshow test: 0.684 .

$1=$ reff.

${ }^{*} \mathrm{P}<0.003,{ }^{* *} \mathrm{p}<0.001$.

AOR, adjusted OR;COR, crude OR.

monitor by physical touch of mothers compared with other WHO recognised key NDSs.

Our findings will have a substantial contribution to improve neonatal health and maternal health-seeking behaviour, particularly in low-income countries through the identification of gaps in knowledge of NDSs among mothers. The findings of this study will have paramount importance to achieve the sustainable development goals and every newborn action plan that targets to achieve 12 or fewer neonatal mortality per 1000 live births worldwide by 2030 . However, this study was not void of limitations. For instance, hawthorn bias/participants might change their behaviour when they feel they are being observed/ and social desirability bias/ participants might not able to reflect their real data regarding obstetric characteristics such as parity and gravidity. Moreover, it might be difficult to generalise the findings of this study due to the reason that this study was conducted among mothers who visit healthcare facilities who had better awareness regarding their own and newborn health.

\section{CONCLUSION}

Maternal knowledge of NDSs was found low. Mothers resided in an urban area, having antenatal follow-up, mothers who had got breastfeeding counselling, mothers who had got postnatal care counselling, multiparous mothers and good practice of essential neonatal care were factors associated with good knowledge of mothers about NDSs. Therefore, healthcare workers should create strategies to promote maternal antenatal follow-up, provide postnatal care counselling to all postpartum mothers before discharge from health facilities particularly 
focusing on NDSs and enhance maternal awareness on essential newborn care practices are recommended.

Acknowledgements The authors are grateful for the data collectors, study participants and Wolkite University.

Contributors AM wrote the proposal and undertook statistical analysis. AM, HA, SS and HS contributed to the writing of the manuscript and equally approved the submitted version of the manuscript.

Funding The authors have not declared a specific grant for this research from any funding agency in the public, commercial or not-for-profit sectors.

Competing interests None declared.

Patient and public involvement Patients and/or the public were not involved in the design, or conduct, or reporting, or dissemination plans of this research.

Patient consent for publication Not required.

Ethics approval To conduct this research, ethical approval was obtained from Wolkite University, the ethical review board with reference number CMHS/012/2020. An official letter was submitted to the Gurage Zone health office. A formal letter was written to each selected hospital and health centre. Informed, voluntary, written, and signed consent was obtained from each study subject prior to data collection.

Provenance and peer review Not commissioned; externally peer reviewed. Data availability statement Data are available on reasonable request.

Open access This is an open access article distributed in accordance with the Creative Commons Attribution Non Commercial (CC BY-NC 4.0) license, which permits others to distribute, remix, adapt, build upon this work non-commercially, and license their derivative works on different terms, provided the original work is properly cited, appropriate credit is given, any changes made indicated, and the use is non-commercial. See: http://creativecommons.org/licenses/by-nc/4.0/.

\section{ORCID iDs}

Ayenew Mose http://orcid.org/0000-0003-4353-7791

Haimanot Abebe http://orcid.org/0000-0001-5885-5982

Solomon Shitu http://orcid.org/0000-0002-9116-1162

\section{REFERENCES}

1 Ministry of Health. Ministry of health neonatal care clinical guidelines, 2018.

2 WHO. Postnatal care of the mother and newborn 2013. World Health Organisation, 2013: 1-72. http://apps.who.int/iris/bitstream/10665/ 97603/1/9789241506649 eng.pdf

3 Hug L, Alexander M, You D, et al. National, regional, and global levels and trends in neonatal mortality between 1990 and 2017, with scenario-based projections to 2030: a systematic analysis. Lancet Glob Health 2019;7:e710-20.

4 World Health Organization. World Health Statistics - Monitoring Health for the SDGs, 2016: 1.121.

5 CSA. Ethiopia mini demographic and health survey; 2016.

6 CSA. Ethiopia mini demographic and health survey; 2019.

7 Federal ministry of health FHD. National strategy for child survival in Ethiopia 2015/16-2019/20 maternal. Magzine Artic 2015;2016:1-74.

8 Shemsi Seid S, Sendo EG, Haso TK, et al. Utilization of integrated management of neonatal and childhood illness (IMNCI) guidelines and associated factors among nurse at public health institutions in West Arsi zone, South East Ethiopia. Clin Mother Child Health 2019;16.

9 Berhanu D, Avan B. Community Based Newborn Care: Quality of CBNC programme assessment - midline evaluation report. London: IDEAS, London School of Hygiene \& Tropical Medicine, 2017.
10 WHO, UNICEF. Reaching Every Newborn National 2020 Milestones [Internet], 2018. Available: https://www.healthynewbornnetwork.org/ hnn-content/uploads/Final-Country-Progress-Report-v9-low-res.pdf

$11 \mathrm{MOH}$. Sustainable Development Goals [Internet].. Available: https:// www.moh.gov.et/ejcc/en/node/19

12 Ekwochi U, Ndu IK, Osuorah CDI, et al. Knowledge of danger signs in newborns and health seeking practices of mothers and care givers in Enugu state, south-east Nigeria. Ital J Pediatr 2015;41:1-7.

13 Bekele F, Bekele K, Mekonnen M, et al. Mothers' knowledge and their health seeking behavior about neonatal danger signs and associated factors in Fiche town, Oromia region, Ethiopia. J Neonatal Nurs 2020;26:324-9.

14 Bulto GA, Fekene DB, Moti BE, et al. Knowledge of neonatal danger signs, care seeking practice and associated factors among postpartum mothers at public health facilities in Ambo town, central Ethiopia. BMC Res Notes 2019;12:549-7.

15 Bayih WA, Birhan BM, Yeshambel A, et al. Determinants of maternal knowledge of neonatal danger signs among postnatal mothers visiting neonatal intensive care unit, North central Ethiopia, 2019: a cross-sectional study. BMC Pregnancy Childbirth 2020;20:1-12.

16 Demis A, Gedefaw G, Wondmieneh A, et al. Women's knowledge towards neonatal danger signs and its associated factors in Ethiopia: a systematic review and meta-analysis. BMC Pediatr 2020;20:1-13.

17 Degefa N, Diriba K, Girma T, et al. Knowledge about neonatal danger signs and associated factors among mothers attending immunization clinic at Arba Minch General Hospital, southern Ethiopia: a crosssectional study. Biomed Res Int 2019;2019:1-8.

18 Guta A, Sema A, Amsalu B, et al. Knowledge of Neonatal Danger Signs and Associated Factors Among Mothers of $<6$ Months Old Child in Dire Dawa, Ethiopia: A Community Based Cross-Sectional Study. Int J Womens Health 2020;12:539-48.

19 Nigatu SG, Worku AG, Dadi AF. Level of mother's knowledge about neonatal danger signs and associated factors in North West of Ethiopia: a community based study. BMC Res Notes 2015;8:4-9.

20 Sakelo AN, Assefa N, Oljira L, et al. Newborn care practice and associated factors among mothers of one-month-old infants in Southwest Ethiopia. Int J Pediatr 2020;2020:1-7.

21 Awasthi S, Verma T, Agarwal M. Danger signs of neonatal illnesses: perceptions of caregivers and health workers in northern India. Bull World Health Organ 2006;84:819-26.

22 Kibaru EG, Otara AM. Knowledge of neonatal danger signs among mothers attending well baby clinic in Nakuru central district, Kenya: cross sectional descriptive study. BMC Res Notes 2016;9:1-8.

23 Abu-Shaheen A, AlFayyad I, Riaz M, et al. Mothers' and caregivers' knowledge and experience of neonatal danger signs: a crosssectional survey in Saudi Arabia. Biomed Res Int 2019;2019:1-7.

24 Welay FT, Kassa NA, Gebremeskel GA, et al. Knowledge of neonatal danger signs and associated factors among mothers who gave birth during the last 4 months while attending immunization services in Harar town public health facilities, Ethiopia, 2017. BMC Res Notes 2019;12.

25 Mersha A. Mother's Level of Knowledge on Neonatal Danger Signs and Its Predictors in Chencha District, Southern Ethiopia. Am J Nurs Sci 2017;6:426.

26 Yosef T, Nigussie T, Asefa A. Knowledge of neonatal danger signs and its associated factors among mothers attending child vaccination centers at Sheko district in Southwest Ethiopia. Int $J$ Pediatr 2020;2020:1-6.

27 Sandberg J, Odberg Pettersson K, Asp G, et al. Inadequate knowledge of neonatal danger signs among recently delivered women in southwestern rural Uganda: a community survey. PLOS One 2014;9:e97253.

28 Adem N, Berhe KK, Tesfay Y. Awareness and associated factors towards neonatal danger signs among mothers attending public health institutions of Mekelle City, Tigray, Ethiopia, 2015. J Child Adolesc Behav 2017;05.

29 Bin ZS, Hossain N, Hussain MA. Factors related to knowledge on newborn danger signs among the recently delivered women in SubDistrict hospitals of Bangladesh. Public Heal Indones 2017;3:50-60. 